\title{
Oncogenic Osteomalacia
}

National Cancer Institute

\section{Source}

National Cancer Institute. Oncogenic Osteomalacia. NCI Thesaurus. Code C67235.

A paraneoplastic disorder affecting the skeletal system. It associated with one of four tumor types: phosphaturic mesenchymal tumor, mixed connective tissue type; osteoblastoma-like tumor; ossifying fibroma-like tumor or non-ossifying fibroma-like tumor. These neoplasms secrete fibroblast growth factor 23, which in addition to causing decreased renal phosphate reabsorption also affects the expression of 25hydroxy-1-alpha-hydroxylase resulting in poor bone mineralization. Clinical signs include fractures, bone pain and muscle weakness. Once lesions are detected, prognosis is extremely favorable as resection most often results in cure. 